\title{
PROCESSOS DE ACUMULAÇÃO POR ESPOLIAÇÃO: O CASO DA MINERAÇÃO DA VALE S.A. EM MOÇAMBIQUE
}

\author{
Ana Paula Saragossa Corrêa ${ }^{1}$ \\ José Gilberto de Souza ${ }^{2}$
}

\begin{abstract}
Resumo: Os processos de extração mineral se constituem exemplo de estratégias de acumulação por espoliação ocorridos em Estados fragilizados e dependentes econômica, social e institucionalmente. Essas táticas determinam as lógicas territoriais de apropriação da terra e da organização social do trabalho, reflexos estes fortemente vivenciados em países africanos, particularmente, em Moçambique. A pesquisa fundamenta-se em um referencial teórico e metodológico que investiga a relação entre a acumulação por espoliação e as comunidades diretamente atingidas pela extração do minério de carvão, tutoreado pela empresa Vale S.A. O presente estudo contempla uma análise de dados secundários disponibilizados por instituições governamentais e não governamentais, com base nas principais atuações da Vale S.A., nos processos de extração mineral. Além disso, a pesquisa tem por objetivo demonstrar as ações e processos geopolíticos dos atores hegemônicos sobre as populações a partir de suas estratégias empresariais da empresa Vale S.A. na extração de carvão nas minas de Moatize e suas determinações territoriais.
\end{abstract}

Palavras-chave: Geopolítica; Acumulação Primitiva; Mina de Carvão; Tete; Moçambique.

\section{PROCESSES OF ACCUMULATION BY DISPOSSESSION IN THE MINING SECTOR: THE CASE OF VALE S.A. IN MOZAMBIQUE}

Abstract: The mineral extraction process are examples of strategies of accumulation by dispossession taking places in fragile and economically, socially and institutionally dependent states. These tactics determine the territorial logic of land appropriation and social organization of labor, which are strongly experienced in African countries, particularly in Mozambique. This research is based on a theoretical and methodological reference that investigates the relation between accumulation by dispossession and the communities directly affected by coal ore extraction supported by Vale S.A. This study includes an analysis of secondary data provided by governmental and nongovernmental institutions, based on the main actions of Vale S.A, in the mineral extraction processes. In addition, it aims to demonstrate the geopolitical actions and processes of the hegemonic actors on the populations based

\footnotetext{
${ }^{1}$ Universidade Federal de Goiás (UFG) - Regional de Jataí, Jataí. anap.saragossa@gmail.com.

${ }^{2}$ Universidade $\quad$ Estadual Paulista (UNESP) $\quad-\quad$ Rio $\quad$ Claror jg.souza@unesp.br. Estudos Geográficos, Rio Claro, 17(1): 292-308, jan./jun. 2019 (ISSN 1678-698X) http://www.periodicos.rc.biblioteca.unesp.br/index.php/estgeo
} 
Processos de acumulação...

on the business strategies of this company in the extraction of coal in the mines of Moatize and its territorial determinations.

Keywords: Geopolitics; Primitive Accumulation; Coal Mine; Tete; Mozambique.

\section{INTRODUÇÃO}

Estados hegemônicos realizaram estratégias de ocupação territorial e acumulação de capital por meio de ações colonialistas de exploração e expropriação. Tais ações constituem a história das colônias portuguesas reverberadas a partir da escravidão da população africana (século XVI ao XIX) que respondem, por exemplo, na formação socioeconômica brasileira (FREYRE, 2003; FURTADO 2007). Moçambique é um exemplo dessa estratégia de apropriação espacial e se configura em campo teórico e empírico das análises das dimensões expropriação e violência. Exemplo da atuação de grupos econômicos capitalistas na coordenação de processos de exploração e seus rebatimentos diretos nas dinâmicas de reprodução social das populações. Essa dinâmica local-global, de relações entre capitais e sociedades autóctones, não se revela em dístico "geográfico areolar", se constitui no desdobramento de um padrão de acumulação mundial com determinações territoriais que se expressam como materialidade das relações de poder no espaço geográfico, o território do capital (SOUZA, 2016; SOUZA, BORGES, 2017). Nos últimos anos do Século XX este país se tornou, do ponto de vista geopolítico e econômico, uma região estratégica para os Estados hegemônicos, diante do alto potencial em exploração agrícola e mineral, vivenciando, assim, processos de intervenção de empresas e explorações de várias magnitudes, uma delas a extração de carvão e pedras preciosas. Moçambique vivenciou inúmeras fragilidades sociais e econômicas marcadas por guerras. Tem uma população de 27 milhões de pessoas e seu Índice de Desenvolvimento Humano (IDH)

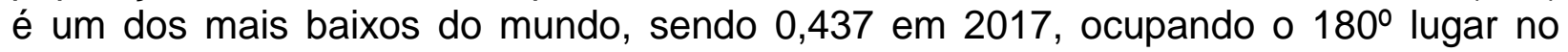
ranking mundial. O Produto Interno Bruto (PIB) de Moçambique em 2016 foi de 35 bilhões de dólares, ficando em $123^{\circ}$ no ranking dado pela Agência de Inteligência Americana. (ONU, 2018; ACIA, 2017).

Dados da balança comercial do país revelam que, no ano de 2015, 34\% do total exportado por Moçambique teve sua origem nas atividades de minérios e metais, obtendo a mesma taxa para a agricultura. O Investimento Direto Estrangeiro (IDE) apresentou aumento significativo, obtendo uma entrada de 3.710,78 milhões de dólares em 2015 contra 107,85 milhões de dólares no ano de 2005, o que ratifica o interesse dos grandes grupos capitalistas na exploração e ocupação do território moçambicano (CONFERÊNCIA DAS NAÇÕES UNIDAS SOBRE COMERCIO E DESENVOLVIMENTO, 2017).

Segundo a Human Rigths Watch (2013) as empresas multinacionais têm investido bilhões de dólares no país nos últimos anos, sendo que uma delas faz parte do objeto dessa análise: a mineradora Vale S.A.

Observou-se que as ações realizadas por empresas multinacionais em territórios africanos ainda têm características imperialistas clássicas (LENIN, 2017). Esse processo se materializa em Moçambique também pela multinacional brasileira Vale S.A. A mudança das estratégias econômicas e geopolíticas brasileiras trouxe uma nova dinâmica nas relações com seus parceiros comerciais e essas ações acabaram influenciando as empresas nacionais a investirem em novos Estudos Geográficos, Rio Claro, 17(1): 292-308, jan./jun. 2019 (ISSN 1678-698X) http://www.periodicos.rc.biblioteca.unesp.br/index.php/estgeo 
territórios estrangeiros. A abertura política brasileira pôde fazer com que empresas nacionais expandissem seus negócios em territórios africanos, realizando empreendimentos com domínio e conhecimento técnico e tecnológico como, por exemplo, a agricultura intensiva e a mineração (ALEM; CAVALCANTI, 2007; DALLA COSTA, 2009).

A análise apresentada se estrutura a partir de dados secundários obtidos junto a órgãos internacionais como o banco de dados do Programa das Nações Unidas para o Desenvolvimento (PNUD), a Agência de Inteligência Americana (CIA), relatório da Human Rigths Watch (2013), bem como dados relacionados ao movimento "Articulação Internacional dos Atingidos pela Vale" e relatório de Governança Corporativa da empresa Vale S.A. Utilizou-se, ainda, reportagens de jornais brasileiros e estrangeiros, que se consubstanciaram em importante base documental para esse estudo.

O objetivo desse artigo é entender as determinações territoriais decorrentes da instalação da Vale S.A. no território moçambicano e sua exploração de minérios em Moatize. O objeto de estudo é perscrutar os impactos territoriais, considerando as mudanças das relações sociais de poder, os aspectos econômicos e a articulação entre Estado e capital, no processo que David Harvey (2005) denomina de acumulação por espoliação. Neste processo, insere-se uma reflexão acerca da atuação da empresa e o conceito de desenvolvimento, como este sentido histórico do capitalismo justifica as articulações do Estado - Capital em território africano e consuma na prestidigitação das nefastas ações imperialistas.

\section{ATINGIDOS PELA VALE EM MOATIZE: RESULTADOS DA ACUMULAÇÃO POR ESPOLIAÇÃO?}

O fim da Guerra Civil e a transição da economia socialista para a de mercado impulsionou um relativo crescimento econômico no país. Apesar dessas premissas, quais são os motivos que levam Moçambique a continuar a ser socialmente desigual? Segundo Castel-Branco (2011), muitas vezes, o pós-conflito é apenas um novo estágio e uma diferente forma do mesmo conflito, pelo qual a guerra se constitui em outra configuração, mais violenta e trocada por outros meios de disputa do poder. A desigualdade econômica medida pelo índice de Gini não alterou significativamente neste período, apontada por 0,54 em 2016 segundo o Banco Mundial (2018). A porcentagem da população que vive na pobreza absoluta não se alterou significativamente nos últimos anos:

[...] a associação estabelecida entre fases iniciais de acumulação e o aumento da desigualdade (por causa da necessidade de aumentar a taxa de poupança para acelerar crescimento económico) nega a experiência histórica de formação do capitalismo na fase de acumulação primitiva. Tanto no caso das economias hoje consideradas desenvolvidas, como no caso de Moçambique e outras economias menos desenvolvidas, a experiência histórica mostra que o processo de acumulação primitiva depende da associação entre o Estado e as forças emergentes da burguesia capitalista para reestruturar a propriedade, o controlo dos recursos e as relações de produção (CASTEL-BRANCO, 2010b, p. 58).

Estudos Geográficos, Rio Claro, 17(1): 292-308, jan./jun. $2019 \quad$ (ISSN 1678-698X) http://www.periodicos.rc.biblioteca.unesp.br/index.php/estgeo 
A política econômica moçambicana foi dominada pelo neoliberalismo e, nos últimos anos, o país tem recebido Investimento Direto Estrangeiro (IDE), em grande parte, no setor minero-energético e continua a depender de ajuda externa para manter sua economia. Os empreendimentos do setor econômico de minas e energia tem geralmente recebido investimentos iniciais da ordem de 500 mil dólares: são definidos como megaprojetos. Castel-Branco (2010, p. 9) relata o seguinte:

[...] depois de uma década de silencio ou de ambiguidades e contradições, o BM e FMI reconhecem oficialmente que os mega projectos pouco ou nada contribuem para a redução da pobreza e para a sustentabilidade do crescimento econômico, e que os incentivos fiscais que lhes são atribuídos os tornam irrelevantes e elevam os seus rácios de custo/benefício social.

As pressões sociais e da comunidade internacional trouxeram reformas legais com o intuito de minimizar os paradoxos os quais a economia de Moçambique se debate, tais como a abundância de recursos naturais e minerais, a quantidade de pessoas pobres no país e, por consequência, a dependência de ajuda externa, uma vez que tais projetos promovem desajustes nas comunidades locais e força processos migratórios campo-cidade, alterando fortemente o padrão de reprodução social das comunidades e, sobretudo das condições de manutenção e acesso a terra (LANGA, SOUZA, HESPANHOL, 2014, MASQUETE, 2018)

Esse processo revela as dimensões globais de coordenação capitalista e alteram, sobremaneira, o padrão das esferas de circulação econômica sem alterar as bases materiais de reprodução social da população. Esse processo de novodependentismo revela que as escalas geográficas local-global não se constituem pares meramente físico-espaciais, mas se configuram, de forma integrada, em bases territoriais de articulação de padrão de acumulação mundial que ganham, notadamente, o movimento de expansão geográfica do capitalismo, integrando tais espacialidades como forma e método de reprodução da acumulação atingindo brutalmente espacialidades e relações não capitalistas. (LUXEMBURG, 1985).

Em Moçambique há uma grande quantidade e variedade de recursos minerais que em sua maioria ainda não foi explorada. Exemplos desses recursos são metais básicos, fosfatos, rochas ornamentais, bauxita, minério de ferro, tantalite, pedras preciosas e semipreciosas, grafites e outros. Além dos exemplos citados há várias jazidas de carvão, a mais conhecida é a Bacia Carbonífera de Moatize, localizada na província de Tete. Esta jazida é considerada até o momento uma das maiores do mundo, com estimativas de reservas de 2,5 biliões de toneladas e se revela na sanha do governo moçambicano para atração de investidores na exploração desses recursos minerais (JOSÉ; SAMPAIO, 2011).

Boaventura de Sousa Santos, em um artigo escrito para o Jornal Correio do Brasil em 2012 expos sua opinião sobre as questões que envolvem a multinacional brasileira e o povo moçambicano:

Estarão os moçambicanos preparados para fugir à maldição da abundância? Duvido. As grandes multinacionais, algumas bem conhecidas dos latino-americanos, como a Rio Tinto e a brasileira Vale do Rio Doce (Vale Moçambique) exercem as suas atividades com muito pouca regulação estatal, celebram contratos que lhe permitem o saque das riquezas moçambicanas com mínimas contribuições para 0

Estudos Geográficos, Rio Claro, 17(1): 292-308, jan./jun. 2019 (ISSN 1678-698X) http://www.periodicos.rc.biblioteca.unesp.br/index.php/estgeo 
orçamento de estado (em 2010 a contribuição foi de 0,04\%), violam impunemente os direitos humanos daspopulações onde existem recursos, procedendo ao seu reassentamento (por vezes mais de um num prazo de poucos anos) em condições indignas, com o desrespeito dos lugares sagrados, dos cemitérios, dos ecossistemas que têm organizado a sua vida desde há dezenas ou centenas de anos (SANTOS, 2012, online).

Estará certa a constatação de Santos (2012)? Mosca e Selemane (2011) também questionam se os megaprojetos trazem algum benefício para Moçambique considerando que há outras potencialidades de extração de valor como gás natural, terra para a agricultura, bauxita e fosfato. As descobertas de carvão de coque, utilizado para a produção de aço, aliadas à grande demanda chinesa e indiana, contribuíram para o aumento do interesse dos investidores estrangeiros.

O megaprojeto da Vale em Moatize, conhecido como "Projeto Moatize", tem a seguinte estrutura: 95\% da participação pertence a Vale, 5\% ao Estado de Moçambique e 10\% de outros investidores. Segundo Mosca e Selemene (2011) os principais financiadores do megaprojeto da Vale em Moçambique são a multinacional IDC e o financiamento do Banco Nacional do Desenvolvimento (BNDES). A área total de exploração é de 23.780 hectares e está localizada no distrito de Moatize, província de Tete (Figura 1). A escala do projeto é grande, pensando na totalidade da economia de Moçambique com um Produto Interno Bruto (PIB) de 11 bilhões de dólares americanos segundo o Banco Mundial em 2016. Em 2017, segundo a própria Vale, a média de produção foi de 11 milhões de toneladas (VALE, 2018) lucrando 330 milhões de dólares americanos. Para 2018, com o corredor de Nacala em funcionamento, a expectativa é subir para 18 milhões de toneladas.

Em 2017 a Vale Moçambique vendeu 15\% de suas ações a Mitsui e Cia. (empresa japonesa). Para o escoamento do produto foi necessário recuperar e ampliar a infraestrutura promovendo a reabilitação do corredor do Norte, realizada com um investimento da Vale num valor estimado em 4 bilhões de dólares, o projeto chamado de Nacala XXI, que totalizou 912 quilômetros, a mesma extensão da Estrada de Ferro de Carajás, implementado mediante um acordo assinado em 23 de outubro de 2009. A construção da linha foi de Moatize até o porto de Nacala, na província de Nampula, operando a partir de maio de 2017, com a projeção de exportar até final de 2018 , o volume total de 18 milhões de toneladas. (MACAUHUB 2013, MOSCA; SELEMANE, 2011, VALE, 2018). Segundo o Relatório Anual da própria empresa (VALE, 2018), o conjunto de infraestrutura e, sobretudo o padrão de extração de carvão determinado pela empresa consolida uma projeção de receita líquida que ultrapasse a casa de dezena de bilhão nos próximos anos, denotando a forma de inserção dependente e subordinada da economia moçambicana no cenário internacional. Será compensatório para a população de Moatize esse empreendimento?

Sobre as questões fiscais há controvérsias a respeito. Segundo matéria veiculada no Jornal O Estado de São Paulo (ROSSI, 2013), o contrato prevê isenção de impostos para os anos iniciais de operação, que são quando os custos de investimento são maiores que as receitas obtidas com a venda do carvão. $O$ contrato também estabelece que a Vale pague $3 \%$ royalties sobre o carvão comercializado ao invés daquele extraído, ou seja, a empresa pagará pelo produto comercializado e não pelo produto extraído. Dessa forma, abre uma vantagem sobre a lucratividade da produção.

Segundo Mosca e Selemane (2011), os megaprojetos se beneficiam de Estudos Geográficos, Rio Claro, 17(1): 292-308, jan./jun. 2019 (ISSN 1678-698X) http://www.periodicos.rc.biblioteca.unesp.br/index.php/estgeo 
incentivos fiscais, de exceções legais e facilidades de operação que, geralmente, outras entidades econômicas não usufruem. Por conta dessas ações governamentais, iniciou-se um debate, pressão e questionamentos sobre os benefícios destinados a esses grupos econômicos e como eles vem se intensificando nos últimos anos.

O contrato com a Vale é um contrato problemático, que arrepia a lei. $\mathrm{Na}$ questão dos royalties, a lei estabelece que eles sejam pagos sobre a produção", diz Adriano Nuvunga, diretor do Centro de Integridade Pública, uma organização de investigação moçambicana. Em agosto de 2013, foi lançada em Moçambique uma campanha que pede a revisão da tributação dos mega-projetos minerais. Fala-se inclusive da renegociação dos contratos já estabelecidos. O da Vale, entre eles (ROSSI, 2013, online).

Segundo o Relatório Anual da Vale S.A. de 2018 (VALE, 2018) o contrato com o governo moçambicano, em relação aos royalties, permanece o mesmo. Além disso, a mineração de carvão é uma das formas mais degradantes ambiental e socialmente de extração de recursos naturais. Esta forma de mineração libera para a atmosfera gases como o metano e o dióxido de carbono (HUMAN RIGTHS WACTH, 2013). Em relação ao prejuízo ambiental e social os royalties deveriam, no mínimo, cobrir esses custos.

A mineração a céu aberto também envolve outros prejuízos como o desmatamento de árvores, a retirada da vegetação deixando o solo exposto a erosões, por exemplo, e destruindo a vida e a biodiversidade local. Outra forma de poluição provocada pela mineração de carvão é a poluição do ar e da água. Segundo José e Sampaio (2011) os processos mineiros são grandes consumidores de água e, nos locais onde existem grandes riscos ao patrimônio ambiental, a mineração precisa ser vedada.

[...] desde a geração e transporte de sedimentos causados por estradas malconservadas durante a fase de exploração até o assoreamento de cursos de água e aumento de partículas sólidas em suspensão nas águas durante a fase de operação da mina (JOSÉ, SAMPAIO, 2011, p. 17).

A poeira e as partículas de carvão, assim como a fuligem libertada ao longo do transporte, contribuem para a poluição do ar, ocasionando problemas respiratórios e até mortais para os trabalhadores das minas de carvão. O carvão exposto à água da chuva ao um corpo d'água, por exemplo, geram a drenagem ácida da mina, um escoamento ácido que contém material tóxico, com metais pesados como o cobre, chumbo, mercúrio e outros podendo poluir corpos d'água e lençóis freáticos. Na Figura 1 podemos observar que a mineração está próxima ao rio Moatize está bem próximo à área de mineração ampliando o risco de contaminação dessa drenagem. Segundo o relatório da Human Rigths Wacth (2013) os Estudos de Impactos Ambientais (EIA) apresentadas pela Vale descrevem os impactos previstos dos seus projetos de mineração e seu planejamento para minimiza-los. O documento mostra que a proximidade da mina aos assentamentos, outras aldeias, à cidade de Tete e ao Rio Zambeze, Revuboé e Moatize (Figura 1) aumenta o risco de impactos à saúde, ao meio ambiente e à economia local, sobretudo no caso quando ocorrem falhas em termos de mitigação:

Estudos Geográficos, Rio Claro, 17(1): 292-308, jan./jun. $2019 \quad$ (ISSN 1678-698X) http://www.periodicos.rc.biblioteca.unesp.br/index.php/estgeo 
[...] os funcionários da Vale [...] mencionaram que as comunidades nos arredores da cidade de Tete estão directamente no caminho da poluição do ar levada pelos ventos predominantes. Numa das fases das operações da mina de Benga, "valores médios horários de concentrações de $\mathrm{NO}^{2}$ excedem as directrizes da OMS de $200 \mathrm{ug} / \mathrm{m} 3$, mas estão dentro do limite legal de Moçambique de $400 \mathrm{ug} / \mathrm{m3}$." Os EIAs para ambas as minas de Moatize e Benga discutem inúmeras potenciais fontes de contaminação da água, bem como de degradação da terra (HUMAN RIGTHS WACTH, 2013, p. 38).

Para que os impactos sejam minimizados é necessário que o governo monitore regularmente os projetos. Ainda não há em Moçambique um processo sólido de fiscalização das questões ambientais, bem como das questões dos regulamentos e penalidades (BATA, 2018). Segundo entrevista a Human Rigths Wacth (2013, p. 45) a vice-ministra do Ministério da Coordenação da Ação Ambiental de Moçambique, Ana Chichava, relatou a problemática sobre a fiscalização ambiental: "A limitação é os recursos. Temos que desenvolver a capacidade da nossa equipe.... Estamos a investir na formação das pessoas, mas também estamos a perder alguns. Estamos a investir em bolsas de estudo, mas há muita concorrência com o sector privado por causa de salários".

Dessa maneira, podemos analisar que os megaprojetos são poucos controlados e não há coordenação sobre os agentes econômicos por parte do governo moçambicano e que as leis atribuídas às questões ambientais ainda estão em níveis de exigência inferiores aos que Organização Mundial da Saúde (OMS) preconiza. Há uma possível realização de dumping ambiental ocorrendo nesses locais, garantindo a acumulação de capital por meio da espoliação e depredação de bens comuns (água e terra, sobretudo).

A acumulação por espoliação aparece nesse momento histórico a partir dessas ações depredatórias de empréstimos, privatizações de recursos os quais pertencentes ao Estado e coaduna suas ações de extração com a precarização de direitos sociais e ambientais (HARVEY, 2006, 2011, 2013).

Estudos Geográficos, Rio Claro, 17(1): 292-308, jan./jun. $2019 \quad$ (ISSN 1678-698X) http://www.periodicos.rc.biblioteca.unesp.br/index.php/estgeo 


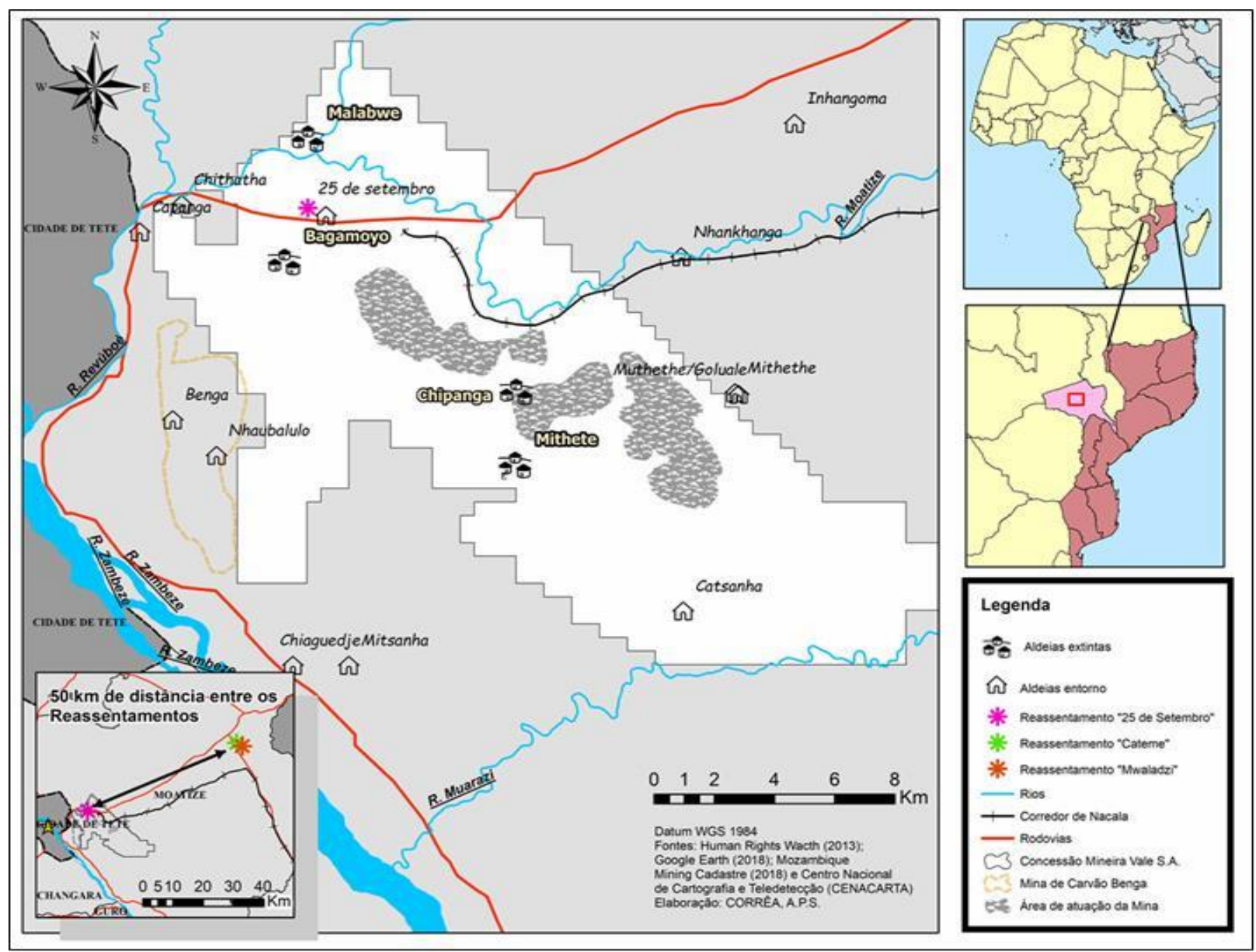

Figura 1 - Mapa de localização dos atingidos pela Vale S.A. em Moatize (2018).

Fonte: Mozambique Mining Cadastre Portal (2018); CENACARTA (2018).

Org. Corrêa; Souza (2018).

A desapropriação das comunidades camponesas é um marco das relações capitalistas observado por Marx (2013), nomeando esse processo de acumulação primitiva. Em 1982 David Harvey, em seu livro The limits to capital, elabora um conceito de acumulação por espoliação, o qual desenvolve de forma mais precisa ao lançar uma análise sobre as mudanças estruturais do capitalismo mundial em seu livro O Novo Imperialismo. O autor aponta que:

Uma reavaliação geral do papel contínuo e da persistência das práticas predatórias da acumulação "primitiva" ou original no âmbito da longa geografia histórica da acumulação de capital é, por conseguinte muito necessária, como observam recentemente vários comentadores. Como me parece estranho qualificar de "primitivo" ou "original" um processo em andamento, substituirei a seguir esse termo pelo conceito de "acumulação por espoliação" (HARVEY, 2005, p. 120).

Nesse contexto, como a Vale S.A. atingiu os reassentados e quais são os montantes de acumulação proporcionados por essas ações? Segundo Mosca e Selemane (2011) os dados que a Vale divulgou não indicam claramente o custo total do reassentamento. Segundo a própria empresa, foram investidos na parte social durante a fase de estudos de viabilidade 7 milhões dólares americanos. A mina de Estudos Geográficos, Rio Claro, 17(1): 292-308, jan./jun. 2019 (ISSN 1678-698X) http://www.periodicos.rc.biblioteca.unesp.br/index.php/estgeo 
carvão da Vale envolveu o reassentamento de 1.365 famílias, em torno de 5 mil pessoas, que viviam aldeias de Chipanga, Bagamoyo, Mithete e Malabwe e foram compensadas financeiramente ou redistribuídas em dois reassentamentos: no Bairro 25 de Setembro e Cateme, a $60 \mathrm{Km}$ de Tete. A transferência da população afetada pelo megaprojeto da Vale aconteceu entre 9 de novembro de 2009 e 28 de abril de 2010.

A Vale reassentou 289 agregados familiares em 25 de Setembro, concebido como um bairro urbano na cidade de Moatize. A compensação não inclui terras agrícolas, mas incluiu bombas de água em cada casa, uma promessa de reformara escola primária e o hospital de Moatize e novas casas. Este reassentamento foi feito para as pessoas que dependem principalmente de empregos assalariados em vez de empregos na agricultura (HUMAM RIGTHS, 2013, p. 46).

A Vale S.A. realizou um Censo para classificar as famílias e dividi-las entre os dois destinos. As famílias foram classificadas em rural e urbana. Segundo esse censo, 717 foram classificadas como rurais e 596 como urbanas. Selemane (2011) acredita que essa separação foi proposital para que não houvesse uma grande articulação entre as populações reassentadas. A reestruturação da propriedade, o controle dos recursos e a organização social da produção formam a mudança e a aceleração do sistema econômico. Por consequência, o aumento da desigualdade é o produto das ações políticas, econômicas e sociais da organização da produção e do controle da riqueza gerada. A relação entre riqueza e pobreza é dada pelo controle do trabalho e dos seus frutos e pela luta política em torno desse controle, onde os termos "desigualdade" e "pobreza" são ações sociais, econômicas e políticas de manifestações dessas tensões e conflitos gerados pelas lutas políticas.

Será que acelerar o crescimento económico com base na exportação em bruto de recursos naturais e na construção de infra-estruturas de apoio à economia extractiva, associado com incentivos fiscais enormes e redundantes, não é uma das premissas que gera mais pobreza (e mais riqueza ao mesmo tempo), que aumenta os preços dos bens básicos de consumo, que reduz as oportunidades e opções para o desenvolvimento articulado e diversificado do País? (CASTELBRANCO, 2010b, p. 7).

A pergunta realizada por Castel-Branco (2010b) pode estar colocada no pressuposto de que a Acumulação por espoliação ou primitiva é necessária para que o engordo do capital possa continuar. Segundo Marx (2013) a acumulação primitiva foi fundamental ao desenvolvimento econômico e ampliação das bases técnicas, sobretudo, das transformações sociais para a instauração do capitalismo, processo esse, ocorrido principalmente no século XVI, responsável pela transição do Feudalismo para o Capitalismo. A acumulação primitiva tonar-se, portanto, importante para entendermos como os capitalistas se tornaram detentores dos meios de produção e ampliaram suas bases de dominação produtiva, política e ideológica. Para o autor, esse processo se deu na forma de captação dos recursos que seriam necessários aos burgueses. Assim foi possível possuir os meios de produção e obter a dominação sobre a força de trabalho dos proletariados. Um processo que segundo Engels; Marx (2010) se estabelece a partir da mudança de paradigmas em toda a sociedade do século XV ao XVII. Exatamente sobre estas profundas transformações as estruturas Estudos Geográficos, Rio Claro, 17(1): 292-308, jan./jun. 2019 (ISSN 1678-698X) http://www.periodicos.rc.biblioteca.unesp.br/index.php/estgeo 
produtivas e as relações sociais de produção no século $\mathrm{XXI}$, há um resgate no processo de acumulação primitiva:

A acumulação por espoliação pode ocorrer de diversos modos e seu modus operandi tem muito de contingente e casual. Apesar disso, é onipresente, sem importar a etapa histórica, e se acelera quando ocorrem crises de sobreacumulação na reprodução ampliada, quando parece não haver outra saída a não ser a desvalorização (HARVEY, 20013, p. 111).

Houve um movimento de resistência, pois algumas famílias não concordaram em mudar-se para os reassentamentos e, desta forma, a Vale proveu assistência para 106 famílias e uma compensação financeira direta para 254 famílias. Os familiares das comunidades reassentadas pela Vale sofreram problemas significativos nos reassentamentos atingindo seus direitos econômicos e sociais, incluindo a autonomia para adquirir comida, água, acesso a trabalho e a saúde (HUMAN RIGTHS WACTH, 2013).

Segundo vídeo divulgado pelo jornal O Estado de São Paulo em 31/10/2013 o líder da comunidade reassentada, Saize Roia, relata o seguinte:

Quando chegou a Vale, quando começou a fazer a pesquisa, falava que todo mundo vai ser reassentado: todos vão ter emprego. Então nós ficamos satisfeitos com a empresa vinha boa (sic). A gente falava assim: boa vinda dessa empresa porque vai acabar com a pobreza. Enquanto era uma política falsa. Desenvolvimento que aparece sempre greve, que desenvolvimento é esse? Não é nenhum desenvolvimento para os reassentados, não! Não! Para aqueles grandes, ou posso dizer para os chefes máximos pode se dizer que há desenvolvimentos. Mas para pessoas que foram reassentadas zero (ROSSI, 2013, online).

Outro morador, Isac Sampanha, afirma que a Vale fez capacitações com alguns moradores em funções como carpinteiros, pedreiros e encanadores entre outros, e estes trabalharam na Odebrecht por um período e depois foram dispensados. Isac reclama que anteriormente eles tinham certa independência econômica por causa da olaria e, agora, isso não é mais possível com a ocupação da empresa no local onde eles fabricavam os tijolos. Segundo pesquisa da Human Rights Watch (2013) as terras agrícolas do reassentamento de Cateme, núcleo rural dos reassentados, as autoridades locais e empresarias reconhecem a baixa qualidade para o plantio e 0 difícil acesso a água:

As comunidades também tiveram as suas opções de trabalho nãoagrícola reduzidas e um abastecimento de água errático. Eles agora vivem a cerca de $40 \mathrm{~km}$ de um grande mercado, em comparação com apenas alguns quilómetros antes do reassentamento (HUMAN RIGTHS WATCH, 2013, p. 48).

Mesmo com a suposta melhora das novas habitações, a troca da casa de madeira pela casa de alvenaria, essas se encontram em péssimas condições com rachaduras e infiltrações, denunciam uma má construção nos reassentamentos:

Estudos Geográficos, Rio Claro, 17(1): 292-308, jan./jun. $2019 \quad$ (ISSN 1678-698X) http://www.periodicos.rc.biblioteca.unesp.br/index.php/estgeo 
As famílias reassentadas em Cateme tiveram que viver sem acesso adequado a terra agrícola de substituição por três anos, devido aos atrasos na alocação de terra por parte do governo. Os agregados familiares em Cateme e Mwaladzi tiveram problemas com 0 abastecimento de água irregular durante meses após 0 reassentamento. (...) Muitas das melhorias de infraestrutura só aconteceram depois do reassentamento e depois de reclamações feitas pela comunidade, tais como a construção de uma estrada de acesso para ligar Cateme à estrada principal (HUMAM RIGTHS WACTH, 2013, p. 52).

A maioria dos reassentados de Cateme eram agricultores e oleiros, vendiam os tijolos, carvão vegetal, lenha, frutas e legumes nos mercados próximos a Moatize. No país é normal encontrar agregados familiares com atividades econômicas primárias, com um pedaço pequeno de terra chamado machamba para a produção de parte de seu alimento. No reassentamento de Cateme, a produção de alimentos caiu de maneira drástica por causa da baixa qualidade do solo. Nas casas onde os reassentados viviam anteriormente tinham terrenos de solos férteis onde podiam plantar culturas de subsistência como o milho e a mapira, no Brasil conhecido como sorgo, hortas nas margens dos rios Zambeze e Revuboé e outros corpos d'agua próximos a aldeia. Terese J. disse ao Human Rigths Wacth o seguinte:

[Antes do deslocamento] eu tinha um grande terreno para a agricultura e uma pequena parcela de legumes. Eu poderia encher o meu armazém de milho. Eu produzia cerca de quatro a cinco sacos de mapira. Nós produzíamos o suficiente para nós mesmos...Às vezes a gente até podia vender [o excedente]. Nós nunca ficávamos muito tempo sem alimentos (HUMAN RIGTHS WACTH, 2013, p. 54).

Segundo pesquisa de campo da Human Rigths Watch (2013), funcionários da Vale e um especialista em agricultura afirmaram que as terras de Cateme são de qualidade variável, sendo que algumas parcelas são incapazes de produzir culturas básicas que antes era possível nas antigas comunidades dos reassentados e sem investimento em irrigação seria impossível haver produção agrícola:

Em resposta à incapacidade dos agricultores de cultivar quantidades suficientes do seu próprio alimento nas suas terras, como faziam anteriormente, tanto a Rio Tinto como a Vale, após atrasos, têm apoiado programas periódicos de distribuição de alimentos. A terra, em muitos casos, é rochosa, distante de fontes de água e imprópria para a produção de uma quantidade e variedade de culturas básicas de preferência: o milho e a mapira (HUMAN RIGTHS WACTH, 2013, p. $55)$.

Os reassentados entrevistados pela Human Rights Watch disseram que antes conseguiam cultivar cerca de quatro culturas diferentes e após o deslocamento somente uma cultura:

Sobrecarregados com a terra pouco produtiva e meios limitados de ganhar rendimento em dinheiro, alguns agregados familiares reassentados batalharam para ter comida suficiente para comer. Senolia S., reassentada em Cateme, disse: "Nós costumamos comer

Estudos Geográficos, Rio Claro, 17(1): 292-308, jan./jun. 2019 (ISSN 1678-698X) http://www.periodicos.rc.biblioteca.unesp.br/index.php/estgeo 
três refeições, pequeno almoço, almoço e jantar. Quando não há comida, podemos passar um dia inteiro sem comer até mesmo sem uma dessas refeições [...]" Eu não posso comer esta casa. Só quero saber onde é que eu posso obter comida."Teresa J. disse à Human Rights Watch:" Eu estou sempre preocupada com comida ... Estou dependente dos meus filhos, às vezes eles dão-me pouco. Quando eu estava em Chipanga, eu produzia a minha comida [...] Cristina L., disse, Estamos sempre preocupados, porque temos filhos. Normalmente temos três refeições por dia. Às vezes, quando vemos a comida a acabar, reparamos que temos de poupar e deixar para o pequeno almoço. Às vezes nós vamos para a cama sem comer. Quando temos menos comida, cozinhamos para os filhos, e eu e o meu marido vamos para a cama sem comida (HUMAN RIGTHS WACTH, 2013, p. 65).

Além dessa problemática da qualidade do solo dos reassentamentos, foram relatados que algumas glebas de terras fornecidas à população pelo Estado já tinham donos, e algumas famílias ficaram sem terras. Segundo a Vale já existiam 67 famílias nessa situação e a Vale só identificou tais problemas após a mudança das famílias reassentadas. Senolia S., uma agricultora de 60 anos de idade, em Cateme, afirmou:

Eu produzi milho no primeiro ano [2010]. No segundo ano, as pessoas vieram e disseram que a terra era delas. Eu deixei o milho que eu já havia plantado. Fui para Vale e disse-lhes que a terra que tinham-me dado pertencia a outros. Eles disseram que iriam dar mais terra. Isto já foi há dois anos (HUMAN RIGTHS WATCH, 2013, p. 58).

Em abril de 2013, os representantes da Vale disseram à Human Rights Watch que, numa decisão do governo da província de Tete, foram oferecidas novas parcelas ou compensações financeiras capazes de substituir a terra de 87 famílias prejudicadas.

Segundo notícia do site "Jornal Minha Terra dos Emigrantes de Luxemburgo" de 26/01/2014 a empresa afirmou que irá indenizar as famílias reassentadas do Bairro 25 de setembro. Em dezembro de 2013 as famílias reassentadas do bairro 25 de Setembro fizeram uma manifestação contra a proposta de indenização fornecida pela Vale e reivindicaram uma compensação justa pelos terrenos agrícolas que perderam com o megaprojeto.

Além do Estado ter fornecido terrenos onde não é possível que os camponeses continuem com suas atividades agrícolas, a Vale ofereceu casas as quais, em poucos anos, já estavam com problemas estruturais. Outro problema enfrentado pelos moradores é a falta de água potável. O reassentamento encontra- se em zonas áridas com ausência de recursos hídricos, uma situação oposta as antigas comunidades (Figura 1). Antes os moradores contavam com os rios Zambeze e Revuboé para a irrigação de suas culturas e pecuária bovina (HUMAN RIGTHS WACTH, 2013).

A solução encontrada pela Vale foi a instalação de bombas d'água nos reassentamentos, porém não foi o suficiente para cobrir a demanda de água da população. Por isso, muitas famílias diminuíram suas quantidades de animais. Muitos gostariam de cultivar hortas, mas não é possível pela escassez da água:

Elvira A., uma moradora de 25 de Setembro, disse: "Estamos a sofrer muito porque estamos a pagar por água enquanto que estamos habituados a ter água de graça e porque estamos a comprar alimentos que costumávamos produzir nós mesmos" (HUMAN RIGTHS WACTH, 2013, p. 71).

Estudos Geográficos, Rio Claro, 17(1): 292-308, jan./jun. 2019 (ISSN 1678-698X) http://www.periodicos.rc.biblioteca.unesp.br/index.php/estgeo 
Antes a população tinha acesso livre a água diretamente nos rios, agora é necessário pagar por ela. Em 2012 a Vale fez alguns reparos para melhorar a distribuição de água tanto em Cateme quanto no 25 de Setembro.

Além das questões físicas, ocorreram impactos psicológicos também nos moradores. Segundo o secretário do Bairro 25 de Setembro:

[...] na verdade, o reassentamento afetou socialmente aos residentes. Se nós formos olhar o simples fato de dizer a um residente que vai deixar a sua zona residencial para ser atribuída outra zona, e neste ato ele deixa de exercer as atividades que anteriormente ele vinha desenvolvendo e passa para uma zona onde não vai fazer nenhuma atividade isso afeta socialmente a pessoa. [...] $E$ isso se notou nos primeiros anos do reassentamento, refiro-me ao ano de 2010 a 2014. Nós fomos notando alguns idosos que depois de terem sido reassentados duas ou três semanas depois perdiam a vida, sobretudo em Cateme (BATA, 2018, p. 433).

Bata (2018) afirma que a chegada dos megaprojetos não melhorou a vida da população de Moatize. Foi possível observar em entrevistas com a população que os benefícios foram poucos expressivos. Para $52 \%$ dos moradores reassentados dos megaprojetos existentes em Moatize não houve melhorias na qualidade de vida. Apenas $27 \%$ da população reassentada respondeu que houve algum tipo de melhoria, sendo que desse montante $21 \%$ conseguem apontar melhorias efetivas em todos os campos (proximidade a hospital, escola, emprego, melhoria de renda).

Estes processos comprimem a perspectiva local-global, as determinações territoriais de infraestrutura promovem os deslocamentos espaciais dos sujeitos, as políticas paliativas pouco ressignificam a vida sócia, as mudanças nas estruturas produtivas e a dependência da economia de mercado que rompe com as relações solidárias-comunais, a perda de referenciais relativos à biodiversidade, a divisão estrutural de comunidades rurais-tribais, a mudança de paradigmas socioculturais de reprodução, sobretudo no que diz respeito às práticas socioespaciais que se consolidam pela ótica e na órbita da mercadoria.

\section{CONSIDERAÇÕES FINAIS}

A acumulação primitiva tonar-se, portanto, um elemento conceitual fundamental para entender os processos de apropriação dos espaços e consolidação territorial na lógica de exploração capitalista. A acumulação de capital é a essência do capitalismo, ou seja, sem a acumulação o capitalismo não se expande geograficamente e esse crescimento produz e reproduz contradições profundas nas formas de organização das sociedades, sobretudo aquelas que têm sua forma de reprodução não estruturadas no valor de troca, na formação de mercadorias.

Observamos dentro do processo da constituição do projeto "Moatize" a desapropriação da população anteriormente residente nesta área, sendo ela realocada em áreas onde essa população não consiga a mesma qualidade de vida, seja ela baixa, por não ter terrenos férteis para a reprodução de sua sobrevivência.

As pesquisas de José e Sampaio (2011) apontam que nessa localidade onde está instalada a multinacional, é uma das maiores jazidas de carvão mineral do mundo. Através desse grande investimento realizado pela Vale S.A., podemos concluir que o

Estudos Geográficos, Rio Claro, 17(1): 292-308, jan./jun. 2019 (ISSN 1678-698X) http://www.periodicos.rc.biblioteca.unesp.br/index.php/estgeo 
retorno esperado com a exploração do carvão mineral será gigantesco, compensando todo o investimento realizado pela mineradora. Por sua vez, os dados apontados em IDE, permitem inferir o quando o capital internacional se territorializou neste país e o quanto de excedente poderá extrair na exploração mineral, considerando as condições ambientais e sociais que o capital internacional se encontra para estabelecer patamares de reprodução ampliada.

Dessa forma, apesar desses megaprojetos desenvolverem de alguma maneira a economia e a infraestrutura do país, fica claro que todo esse investimento realizado pela Vale S.A. não terá um retorno para a população moçambicana, talvez alavancará a economia do país, mas os Índices de Desenvolvimento Humano continuarão baixos, e dependente de nova perspectiva política para que haja um melhor investimento dessas empresas por meio de uma carga tributária que permita fazer jus às demandas sociais que se apresentam ao país. Evidentemente tais determinações territoriais implicam em relações profundas com o Estado e a Vale S.A., que reconfiguram as espacialidades, dentre elas a espacialidade política o que nos faz reconhecer que tais processos apropriativos do espaço moçambicano, em suas múltiplas dimensões, consolidam territórios hegemônicos para atuação e perpetuação da expansão geográfica do capital, mediadas pelo conceito de espoliação dos territórios.

\section{REFERÊNCIAS}

AGÊNCIA de Inteligência Americana. The world factbook. Disponível em: https:/www.cia.gov/library/publications/the-world-factbook/geos/mz.html Acesso em: 24 jul. 2017.

ALEM, Ana Cláudia; CAVALCANTI, Carlos Eduardo. 0 BNDES e 0 apoio à internacionalização das empresas brasileiras: algumas reflexões, in: ALMEIDA, André (org.). Internacionalização de empresas brasileiras. Perspectivas e riscos. Rio de Janeiro: Elsevier, p. 259-282, 2007.

ARTICULAÇÃO Internacional dos Atingidos pela Vale. Relatório de Insustentabilidade da Vale 2012. Disponível em: http://atingidospelavale.wordpress.com/2012/04/18/relatorio-de-insustentabilidade-da- vale2012/. Acesso em: 28 dez. 2012.

BANCO Mundial. Moçambique: aspectos gerais. Disponível em: https://www.worldbank.org/pt/country/mozambique/overview. Acesso em: 15 out. 2018. BANCO Mundial; INSTITUTO de pesquisa econômica aplicada (IPEA). Ponte sobre o Atlântico: Brasil e África Subsaariana. Parceria Sul-Sul para o Crescimento, 2011. Disponível em <http://www.ipea.gov.br/portal/index.php?option=com_content\&view=article\&id=12637>. Acesso em: 12 set. 2012.

BATA, Eduardo J. Entre estatais e transnacionais, "quantos ais": efeitos espaciais dos megaprojetos de mineração do carvão em Moatize, Moçambique. 2018. 565f. Tese (Doutorado em Geografia), Programa de Pós- Graduação em Geografia, Instituto de Estudos Socioambientais, Universidade Federal de Goiás. Goiânia (GO). 2018.

Estudos Geográficos, Rio Claro, 17(1): 292-308, jan./jun. 2019 (ISSN 1678-698X) http://www.periodicos.rc.biblioteca.unesp.br/index.php/estgeo 
CASTEL-BRANCO, Carlos N. Economia Extractiva e Desafios de Industrialização em Moçambique. Cadernos IESE, Maputo, no01/2010, 2010.

CASTEL-BRANCO, Carlos N. Pobreza, Riqueze e Dependência em Moçambique: a propósito do lançamento de três livros do IESE. 2010b.

CONFERÊNCIA DAS NAÇÕES UNIDAS SOBRE COMÉRCIO E DESENVOLVIMENTO. General Profile: Mozambique. Disponível em: http://unctadstat.unctad.org/CountryProfile/GeneralProfile/en-GB/508/index.html. Acesso em 24 jul. 2017.

DALLA COSTA, Armando. La Vale dans le nouveau contexte d'internatonalisation des entreprises brésiliennes. Revista Entreprises et Histoire, Paris, n. 54, abril 2009,

p. 86-106. Disponível em: https://www.cairn.info/revue-entreprises-et-histoire-2009-1page-86.htm. Acesso em: 22 jul. 2017.

FREYRE, Gilberto. Casa-grande \& senzala. 48. ed. São Paulo: Global, 2003.

FURTADO, Celso. Formação Econômica do Brasil. 32. ed. São Paulo: Companhia Editora Nacional, 2007.

HARVEY, David. A produção capitalista do espaço. Tradução Carlos Szlak. 2 ed. São Paulo: Annablume, 2006.

HARVEY, David. O enigma do capital e as crises do capitalismo. Tradução João Alexandre Peschanski. 1 ${ }^{\underline{a}}$ ed. São Paulo: Boitempo, 2011.

HARVEY, David. O Novo Imperialismo. Tradução Adail Sobral e Maria Stela Gonçalves. $7^{\text {ạ }}$ ed. São Paulo: ed. Loyola, 2013.

HUMAN RIGHTS WATCH. O que é uma casa sem comida? O boom da Mineração de Carvão e o Reassentamento. Estados Unidos da América, HWT, 2013.

JOSÉ, David Selemane; SAMPAIO, Carlos Hoffmann. Estado da arte da mineração em Moçambique: caso carvão de Moatize, Tete. III Congresso Brasileiro de Carvão Mineral, anais de congresso 2011 Gramado RS.

LANGA, José Maria do Rosário Chilaúde; SOUZA, José Gilberto, HESPANHOL, Rosângela Aparecida de Medeiros. A produção de alternativas agroenergéticas e a questão da terra em Moçambique: A província de Manica. Campo-Território: Revista de geografia agrária, v. 8, n. 15, p. 1-31, fev., 2013. Disponível em: http://www.seer.ufu.br/index.php/campoterritorio/article/viewFile/19768/12062. Acesso em: 25 jul. 2017.

LUXEMBURG, R. A acumulação de capital: contribuição ao estudo econômico do imperialismo. São Paulo: Nova Cultural, 1985 [1913].

Estudos Geográficos, Rio Claro, 17(1): 292-308, jan.jjun. 2019 (ISSN 1678-698X) http://www.periodicos.rc.biblioteca.unesp.br/index.php/estgeo 
MARX, Karl. O Capital: Crítica da economia política. Livro I: o processo de produção de capital. Tradução Rubens Enderle. 1aㅡ ed. São Paulo: Boitempo, 2013.

MASQUETE, J. A. Expansão Urbana no Município de Lichinga (Moçambique - África): Agentes, Processos e Políticas. Campinas: UNICAMP, 2018. (Tese Doutorado em Geografia).

MINA de Moatize, Vale S.A., s.d. Disponível em: http://www.vale.com/mozambique/PT/business/mining/coal/moatize-coalmine/Paginas/default.aspx. Acesso em 10 ago. 2018.

MOÇAMBIQUE e Brasil juntam-se hoje na inauguração do Corredor de Nacala, Diário de Notícias, Lisboa, 12 mai. de 2017. Disponível em: http://www.dn.pt/lusa/interior/mocambique-e-brasil-juntam-se-hoje-na-inauguracao-docorredor-de-nacala-8469587.html. Acesso em: 15 jul. 2017.

MOÇAMBIQUE: 1365 famílias reassentadas pela Vale recorrem ao governo do país para garantir direitos. Atingidos pela Vale, 26 de out. 2012. Disponível em: http://atingidospelavale.wordpress.com/2012/10/29/mocambique-1365-familiasreassentadas-pela-vale-recorrem-ao-governo-do-pais-para-garantir-direitos-2/. Acesso em: 10 jan. 2014.

MOSCA, João; SELEMANE, Tomás. El dorado Tete: os mega projectos de mineração. Maputo: Centro de Integridade Pública, 2011.

ONU revê em alta dados de Moçambique, nono país menos desenvolvido do mundo. Diário de Notícias, Lisboa, 14 de set. 2018. Disponível em https://www.dn.pt/lusa/interior/onu-reve-em-alta-dados-de-mocambique-nono-pais- menosdesenvolvido-do-mundo-9846107.html. Acesso em 20 dez. 2018.

PROGRAMA das Nações Unidas para 0 Desenvolvimento. Relatório de Desenvolvimento Humano $2015 . \quad$ Disponível em http://www.br.undp.org/content/brazil/pt/home/idh0/rankings/idh-global.html. Acesso em: 24 jul. 2017.

ROSSI, Amanda. Vale se torna a maior investidora do Brasil na África e é alvo de críticas, O Estado de São Paulo, São Paulo, 31 out. 2013. Disponível em: http://www.estadao.com.br/noticias/cidades,vale-se-torna-a-maior-investidora-do-brasil- naafrica-e-e-alvo-de-criticas, 1091746,0.htm . Acesso em: 19 jan. 2014.

SANTOS, Boaventura de Sousa. Moçambique: a maldição da abundância? Correio do Brasil, Rio de Janeiro, 25 de jul. 2012. Disponível em: http://correiodobrasil.com.br/mocambique-a-maldicao-da-abundancia/491145/. Acesso em: 10 de jul. 2017.

\section{SEMPRE a Vale Moçambique. Articulação Internacional do Atingidos e Atingidas pela} Vale, 19 jun. 2014. Disponível em: https://atingidospelavale.wordpress.com/2014/08/10/sempre-a-vale-mocambique. Acesso em: 10 de jul. 2017.

Estudos Geográficos, Rio Claro, 17(1): 292-308, jan./jun. 2019 (ISSN 1678-698X) http://www.periodicos.rc.biblioteca.unesp.br/index.php/estgeo 
SOUZA, J.G.; BORGES, A. C. G. As determinações territoriais da lógica do valor e do autovalor ? análise da produção de soja no Mato Grosso ? Brasil. In: Rui Jacinto. (Org.). Iberografias: Outras Fronteiras, Novas Geografias: Intercâmbios e Diálogos Territoriais. 32 ed. Coimbra: Ancora Ed./Centro de Estudos Ibéricos (CEI), 2017, v. 32, p. 247-270.

SOUZA. J.G. Local-Global: território, finanças e acumulação na agricultura. In: LAMOSO, L.P. (Org.). Temas do desenvolvimento econômico brasileiro e suas articulações com o Mato Grosso do Sul. 1 ed. Curitiba-PR: Ithala, 2016, v. 1, p. 26- 54.

VALE S.A. Relatório Anual 2017. Disponível em: http://www.vale.com/brasil/PT/investors/information-market/annualreports/20f/Paginas/default.aspx. Acesso em: 20 set. 2018. 